\title{
Endoscopic Endonasal Transsphenoidal Approach for Pituitary Adenomas: a Prospective Review of Our Early Experience
}

\author{
Rostam Poormousa ${ }^{1}$, Kaveh Haddadi ${ }^{2}$, Misagh Shafizad ${ }^{3}$, Sajjad Shafiee ${ }^{3}$ \\ ${ }^{1} \mathrm{MD}$, Assistant Professor of Otorhinolaryngology, Bo'ali Hospital, Mazandaran University of Medical Sciences, Sari, Iran \\ ${ }^{2} \mathrm{MD}$, Associate Professor of Neurosurgery, Orthopedic Research Center, Neurosurgery Department, Imam Hospital, Mazandaran university of medical \\ Sciences, Sari, Iran \\ ${ }^{3} \mathrm{MD}$, Assistant Professor, Neurosurgery Department, Imam Hospital, Mazandaran University of Medical Science, Sari, Iran \\ *Corresponding Author Address: Neurosurgery Department, Imam Hospital, Mazandaran University of Medical Science, Sari, Iran. Tele- \\ fax: +98-11-33378789. Postal code: 48166-33131
}

Article Type: Research Article

Received: March 17, 2016, Last Revised: July 24, 2016, Accepted: July 25, 2016

\section{Abstract}

Background \& Aim: Pituitary adenomas are part of a dissimilar group of benign neoplasms. The development of endoscopic techniques for surgery of paranasal sinuses has increased the opportunity for an endoscopic approach with regard to the pituitary gland. Minimally invasive endoscopic pituitary surgery, in turn, permits a more thorough tumor resection and fewer associated surgical complications. This study aimed to determine the descriptive outcomes and the complication rates for endoscopic transsphenoidal hypophysectomies.

Methods \& Materials/Patients: A prospective study was conducted from November 2012 to March 2015.28 patients with proven symptoms of pituitary adenomas were included in this study, and regularly attended follow-up sessions.

Results: In our study, we have operated on 28 patients with hypophysis adenoma with the help of an endoscopic setting. The male to female ratio was $1: 2.5$, with average age range of 35 to 45 years. Growth hormone (GH) adenoma appeared in $36 \%$ (10 patients), prolactinoma in $21 \%$ (6 patients), Cushing's disease in $18 \%$ (5 patients) and non-functional adenoma in $18 \%$ ( 5 patients). Gonadotroph adenomas were the least common at about $7 \%$. The most common symptoms in our series were headache and visual defects. 5 patients including 2 with prolactinoma and 3 with $\mathrm{GH}$ adenoma presented apoplexy signs and symptoms.

Conclusion: Our series demonstrated that the endoscopic approach not only allows well anatomical visualization, and therefore facilitates the full oncological resection of tumors, but also reduces the incidence of pre-operative complications.

Keywords: Endoscopic; Surgery; Transnasal; Hypophyseal, Pituitary Adenoma

Please cite this paper as: Poormousa R, Haddadi K, Shafizad M, Shafiee S. Endoscopic Endonasal Transsphenoidal Approach for Pituitary Adenomas: a Prospective Review of Our Early Experience. Iran. J. Neurosurg. 2016;2(1): 6-10.

\section{Introduction}

Pituitary adenomas are part of a dissimilar group of benign tumors. The hormonally-active tumors present with well-recognized syndromes and consist of growth hormone adenoma, prolactinoma, and corticotrophin adenoma. The hormonally-inactive ones, more often than not comes to clinical consideration secondary to local mass effect or due to pituitary insufficiency. Pituitary adenomas can present in any age, and similarly affect males and females. The clinical presentation of pituitary adenomas varies, depending upon the location and severity of the tumor. Horsely (1906) decompressed the pituitary gland by the transcranial route for the first time (1). Then, in 1909, Cushing started sub-labial transseptal operations (2). This technique was promoted by Guiot (3) and Hardy (4) with the appearance of the operative microscope. A trans-sphenoidal approach was performed in the late 1970s and early 1980s.

The progress of endoscopic techniques for paranasal sinuses surgery (5) revealed the opportunity for an endoscopic pituitary gland approach. Jankowski et al. (6) described the endoscopic endonasal removal of pituitary adenomas in 3 patients. The pure endonasal endoscopic surgery of pituitary tumors was developed by Jho and Carrau $(7,8)$. On that point there is still some debate regarding the effectiveness of pituitary endoscopic surgery.

Minimally invasive procedures in neurosurgery, during the last two decades, have become an invariable subject of work and valuation.
Skull Base Surgery, as with other disciplines, has taken this approach with the introduction of the endoscopic endonasal anterior approach. The root of this attack to the sella turcica has been assigned to the work of researchers such as Carrau, Jho, Cappabianca and Frank among others (9-11).

With advent of modern endoscopic tools, the impetus in the subject area of endoscopic pituitary surgery has excited interest. This has shown that endoscopes offer more comprehensive pictures of the pituitary gland and its surrounding structures than does an operating microscope. Minimally invasive endoscopic pituitary surgery, in turn, allows for a more thorough tumor resection, and fewer associated surgical complications. Thus, the endoscopic, transnasal management of pituitary gland neoplasms is an extensively established alternative to the traditional microscopic approach. We introduced endoscopic surgery in our hospital in 2012 with a multidisciplinary schedule between the neurosurgery and neuroendocrine departments. We worked with the Lotta endoscopic system made by Storz Company. This study aimed to determine the descriptive outcomes and the complication rates for endoscopic trans-sphenoidal hypophysectomies reported to date in our hospital from 2012 to 2015. There was no history of pituitary surgery using nasal trajectory, either conventional or endoscopic, in our center before these presented data. 


\section{Methods and Materials}

The study was approved by the local institutional ethics committee. Written informed consent was obtained from each patient before surgery. A prospective study was carried out from November 2012 to March 2015. 28 patients with proven cases of pituitary adenomas were included in this survey as they regularly attended follow up sessions. All patients were admitted for endoscopic surgery based on neurosurgical and endocrine indications. Demographic features, imaging and lab findings, visual testing, neuro examination findings before and after surgery were recorded. Patients were followed up at least for 1 year with MRI, lab testing and visual testing. Preoperative sagittal and coronal Gd-MRI and reconstruction paranasal sinuses CT scans were performed for all patients.

The sample consisted of 20 adult females and 8 males. The age ranged from 17 to 65 years, with median age of 42 years-old.

The tumors were divided in micro adenomas $(<1 \mathrm{~cm})$ and macro adenomas $(>1 \mathrm{~cm})$. The macroadenomas were further sorted in terms of their extensions in the suprasellar (SS), intrasellar (S) and invasion of the cavernous sinus (CS).

The following parameters were evaluated preoperatively and three months after the procedure. These included symptoms, neuroradiologic imaging, endocrinological assessment (measurement of progesterone, estradiol, testosterone, prolactin (PRL), free thyroxin, thyrotropin (TSH), cortisol, corticotrophin $(\mathrm{ACTH})$, luteinizing hormone $(\mathrm{LH})$, growth hormone $(\mathrm{GH})$, follicle stimulating hormone (FSH), insulin-like growth factor-1) and ophthalmologic examination of pa-tients with radiologic or clinic evidence of chiasmal compression. We investigated the immunohistochemistry and the histology of the lesions in all cases. By postoperative magnetic resonance imaging (MRI), we determined the degree of surgical resection such as partial resection $(<80 \%)$, subtotal resection $(\geq 80 \%)$ and total macroscopical resection (100\%) (17).

\section{Surgical Procedure}

We used the surgical technique proposed by Jho and Carrau with minor changes $(12,13)$. The patients were under oral tracheal intubation and general anesthesia, in a supine position with the head slightly flexed and turned ten degrees toward the surgeon. The head was fixed with a standard 3-pin-holder. The video monitor was placed in front of the operating surgeon and behind the patient's head. The patient's face, nasal and oral cavities were prepped and draped in an aseptic manner. In order to prevent the aspiration of blood at the time of extubation, a gauze roll was placed in the oropharynx. The patient was given ceftriaxone and clindamycin 30 minutes before the surgery and for three days after it. A topical vasoconstrictor was used for washing both nostrils. In the case of patients with normally pneumatized sphenoid sinus, intra operative image guidance was not necessary. Anatomical landmarks were identified for all operations. In all cases, we used a 0-degree endoscope connected to an irrigation / suction device with a lens with diameter of $4 \mathrm{~mm}$. We did not use neuronavigation for beginning of surgery.

We always applied a binostril approach. The procedure was separated into nasal and sellar phases.

Nasal phase: In this step the surgeon took an instrument in his favored hand and the endoscope in the other hand. The middle turbinate was lateralized, and the sphenoid ostia was placed bilaterally. A wide sphenoidotomy was followed by the removal of the intrasinusal, and inter septa, and the clivus, carotid prominences, sellarfloor, opticocarotid recesses and planum sphenoidale were exposed (Figure 1).

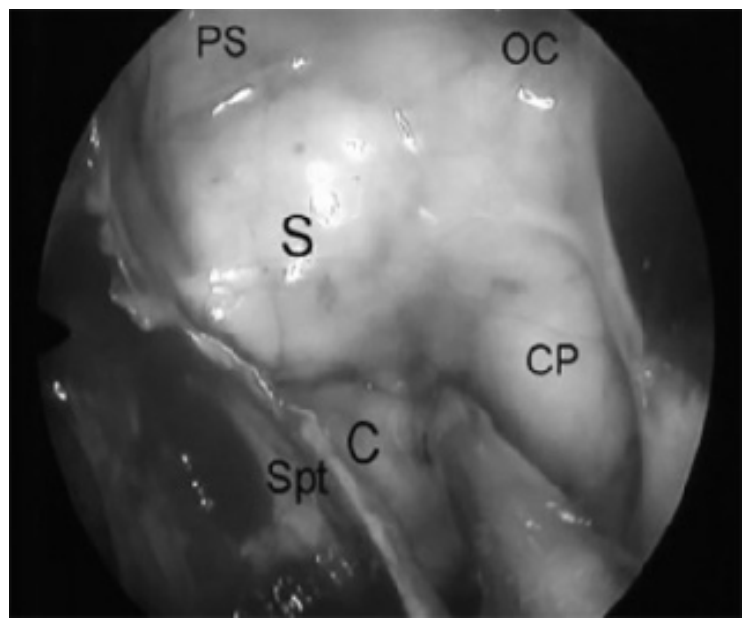

Figure 1. Endoscopic View of the Sphenoidal Sinus with the Right Side Partially Covered by an Intrasinusal Septum [Spt], Clivus [C], Sellar Floor [S], Planum Sphenoidale [PS], Carotid Prominence [CP], Opticocarotid Recess [OC]

Sellar phase: The surgeon applied a "three-hand" technique. An assistant operated the endoscope in order to afford the surgeon the possibility of working with two tools. Bimanual dissection was then performed. With a high-speed drill, the sellar floor was removed. The dura mater was opened and the sellar content was exposed.

We tried to protect the normal pituitary tissue. The surgeon took away the sellar tumor using a standard neurosurgical technique. Then in the case of patients with macroadenomas, the endoscope was situated inside the sella and a careful search was made for miscellaneous tumors. The endoscope with further heading using an additional head in the suprasellar region in the case of macroadenomas with suprasellar extensions, and the tumor was removed.

In patients with significant preoperative cerebrospinal fluid (CSF) leak, a multilayer sellar reconstruction was made by using fascia lata, fat graft, gel foam and fibrin glue, and nasal vascularized flaps. In cases without a preoperative CSF leak, only gel foam and fat were used to close the sella. All patients signed an informed consent form.

\section{Results}

In our study, we reported on the operation of 28 patients with hypophysis adenoma with the help of an endoscopic setting. In this study, the male to female ratio was $1: 2.5$, with average age of 35 to 45 years.

In our series, $25 \%$ of patients had microadenoma whereas patients with macroadenoma made up $75 \%$. Figure 2 shows the percentage of all kinds of adenoma in our surgery series; we have not seen any cases of TSH adenoma.

$\mathrm{GH}$ adenoma accounted for 36\% (10 patients), prolactinoma for $21 \%$ (6 patients), Cushing's disease 18\% (5 patients), non-functional adenoma $18 \%$ (5 patients). Gonadotroph adenomas were the lowest at about $7 \%$.

The most common symptoms accounted for in our series were headache and visual defects. 5 patients (2 prolactinoma and $3 \mathrm{GH}$ adenomas) presented with apoplexy signs and symptoms.

\section{Non-functioning adenomas}

There were four macroadenomas with sellar and suprasellar 


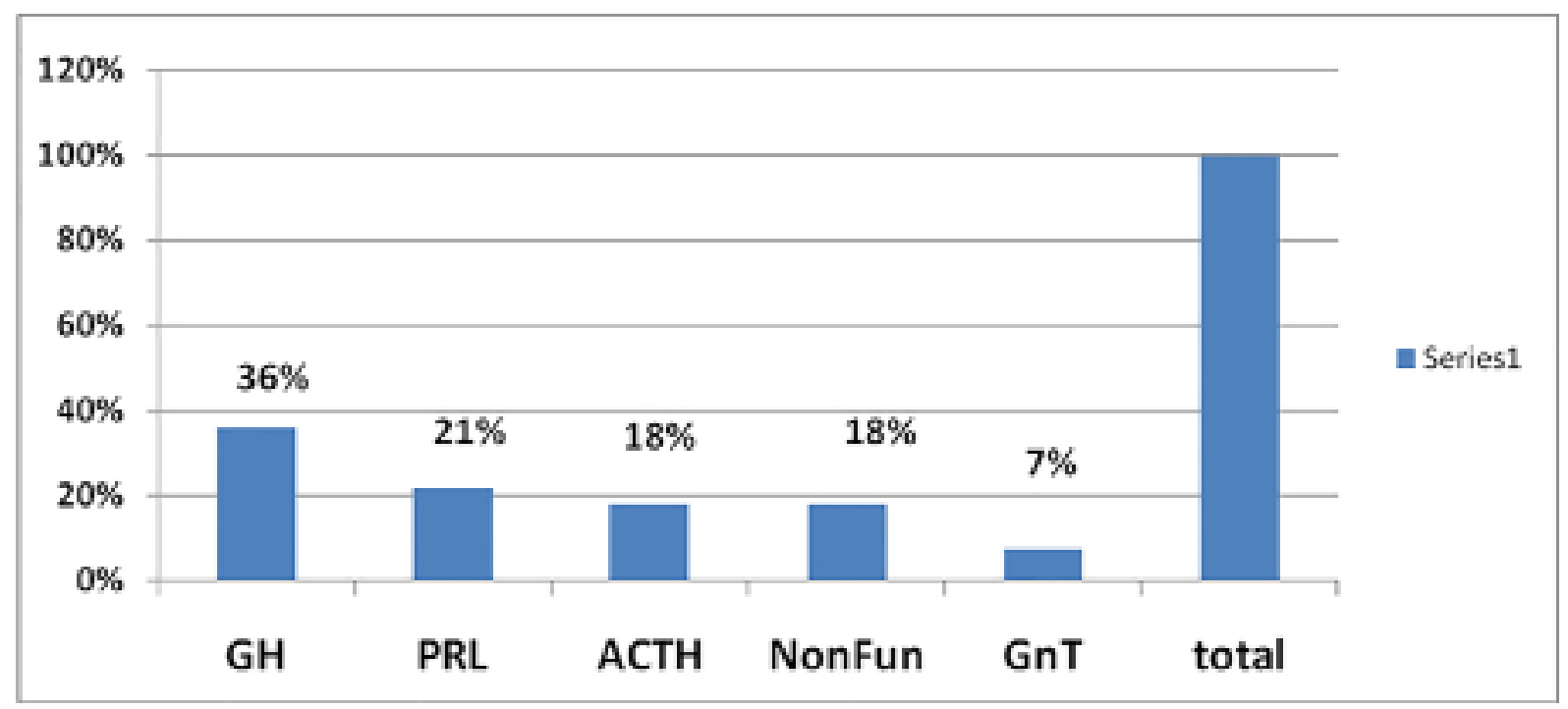

Figure 2. Percentage of All Kind of Adenoma in our Surgery Series
Note: GH= Growth Hormone Adenoma, $P R L=$ Prolactinoma, ACTH=ACTH-secreting Adenomas, NonFun= Non Functional Adenoma, GnT= Gonadotroph Adenoma

extensions. One macroadenoma had additionally cavernous sinus invasion. In three cases the tumor was removed totally, and in one case sub-totally (more than $80 \%$ ).

Three null cell tumors and two LH and FSH secreting-adenomas were seen in the immunohistochemistry of the lesions.

\section{ACTH-secreting adenomas}

Clinical, endocrinological and immunohistochemical assessment confirmed Cushing's disease in five patients, one macroadenomas and four microadenomas. All microadenomas and one case of macroadenoma were limited to the sella resected totally and hormonal level of the disease was controlled (postoperative plasmatic cortisol levels $<7 \mathrm{mg} /$ deciliter)

\section{GH-secreting adenomas}

$\mathrm{GH}$-secreting adenomas were confirmed in ten acromegalic patients. A normal hormonal level was defined as $\mathrm{GH}<1.0 \mathrm{ng} / \mathrm{ml}$ and GH after glucose load $<0.4 \mathrm{ng} / \mathrm{ml}$ and normal levels of IGF-1 for age. Gross macroscopical tumors were removed and hormonal control was acquired in three cases of microadenomas, in four cases of macroadenoma limited to the sella and in two cases of sellar and supraselar macroadenoma. For these patients, no supplementary therapy was necessary.

One patient with sellar/supraselar macroadenoma and one case with cavernous sinus invasion were sub totally removed. Gross macroscopical removal was achieved in the patient with a residual tumor in sellar/supraselar and lack of control with octreotide was seen in one case of cavernous sinus invasion which was then submitted to radio surgery.

\section{Prolactin-secreting adenomas}

Sudden visual deterioration and oculomotor nerve paralysis was seen in one patient with giant prolactinoma. After complete resection of the tumor, the neurological deficits were improved and the prolactin level was normalized. In addition, three patients with refractory macroadenoma were treated to long term cabergoline medication, and one with cystic prolactinoma in MRI and single women because fertility concerns had undertaken endoscopic transnasal surgery with a total resection of the tumor leading to improvement in hormonal levels in the long term follow up.

\section{Gonadotrop-Secreting Adenomas}

One patient with macro adenoma and sexual disorders, according to his clinical and immuno-histochemical and endocrinological evaluation, had undergone endoscopic surgery with totally resection of the tumor and one had unergone a subtotal resection. Both were satisfied in the long term period following surgery. Table 1 reviews the overall quantity of tumor removal compared with tumor extension and size. Table 2 reviews pre- and post-surgical visual disturbances compared with the tumor size extension.

Table 1. Tumor Extension and Removal

\begin{tabular}{|l|c|c|c|c|}
\hline & \multicolumn{4}{|c|}{ Tumor Removal } \\
\hline \multicolumn{1}{|c|}{ Extension } & No.Patient & Total & Subtotal & Partial \\
\hline Microadenoma & 7 & $7(100 \%)$ & - & - \\
\hline Macroadenoma & 21 & & & \\
\hline S & 9 & $7(77 \%)$ & $2(23 \%)$ & - \\
\hline S,Ss & 10 & $8(80 \%)$ & $2(20 \%)$ & - \\
\hline S,Ss,Cs & 2 & $1(50 \%)$ & - & $1(50 \%)$ \\
\hline Total & 28 & $23(82 \%)$ & $4(14.2 \%)$ & $1(3.5 \%)$ \\
\hline
\end{tabular}

Note:S: sellar; SS: suprasellar; CS: cavernous sinus

Table 2. Visual Improvement and Tumor Extension

\begin{tabular}{|l|c|c|}
\hline & \multicolumn{2}{|c|}{ Visual Disturbance } \\
\hline Extension & Pre-operative & $\begin{array}{c}\text { Post-operative } \\
\text { Improvement }\end{array}$ \\
\hline Microadenoma & 0 & 0 \\
\hline S & 4 & 4 \\
\hline S,SS & 8 & 6 \\
\hline S,SS,SC & 2 & 1 \\
\hline Total & $50 \%(14.28)$ & $78.5 \%(11.14)$ \\
\hline
\end{tabular}

Note:S: sellar; SS: suprasellar; CS: cavernous sinus. 


\section{Clinical presentation}

The most common complaint before diagnosis of pituitary adenoma was visual impairment (visual field and acuity) in 50\% (14); followed by headache in $42 \%$ (12), amenorrhea in $17 \%$ (5), ophthalmoplegia in 3\% (1). 2 prolactinoma and $3 \mathrm{GH}$ adenoma patients presented with apoplexy signs and symptoms. The median time between the appearance of the symptoms and diagnosis was 22 months.

\section{Intraoperative findings}

We established an intra-operative CSF leak in 39\% (11) of patients, suprasellar arachnoids membrane prolapsed in $21 \%(6)$, and an incidence of $3 \%$ (1) for intraoperative hemorrhage.

\section{Complications}

The overall incidence of complications was $11.22 \%$ (11). The most common was a postoperative CSF leak in 10\% (3) followed by postoperative hematoma 3\% (1) and hydrocephalus 3\% (1). We didn't have any vascular injury, especially to the carotid artery. The incidence of complications such as epistaxis, sphenoid sinus problems, endocrine insufficiency, visual disturbance, postoperative hemorrhage, cranial nerve injury and mortality were significantly lower than other complications. There were no deaths related to the tumor operation. One of our patients had postoperative hematoma with visual field disturbance that was improved by emergency evacuation. One patient suffered complications with a shunt-dependent hydrocephalus after an acute period of surgery, and 3 patients had CSF leakages that needed to be explored. 53\% (18) of the patients suffered a transient electrolyte imbalance and diabetes insipidus-like syndrome that improved with medication. There were no incidences of permanent electrolyte imbalance, meningitis or infection.

\section{Clinical results}

We found visual improvement in 78.5\% (11 of 14 visual field disorders) and we received one case $(8.4 \%)$ of permanent progressive visual deterioration. One patient called for surgical reintervention for a remnant tumor subtotal resection. Total tumor resection was confirmed in over $82 \%$ of primary cases, with biochemical remission in $86 \%$.

\section{Discussion}

The varied practice of using endoscopes in all surgical procedures has extended neurosurgical procedures in a retarded method. The highpoint for the expansion of endoscopic endonasal pituitary surgery was the previously demonstrated otorhinolaryngologic skill with endoscopic surgery for paranasal sinuses (5).

The endoscopic approach has clear benefits compared to traditional transseptal sublabial microscopic surgery. Nasal speculum isn't necessary, so this approach avoids a sublabial opening, fracture of the nasal septum and dissection of septal mucosa. Consequently, postoperative morbidity is reduced (14). It narrows the surgical strip, thereby limiting the visual field and the manipulation of instruments. The endoscopes provide better visualization of anatomical landmarks because it offers a wide angle of view. Anatomical landmarks were used in the endoscopic approach, therefore it avoids intraoperative fluoroscopy, usually used in traditional surgery, and the exposure of patients to radiation therapy is reduced.

Another benefit of endoscopic surgery is the search of tumor remnants. Such remnants may not accessible with microsurgery because the microscope cannot access the supraselar region and the sella turcica.

Rates of tumor removal reflect different stages of the learning curve and the development of surgical techniques, thus, the writing with regard to pituitary surgery has changed significantly (14-16). Santos et al. described a retrospective analysis of 30 patients with pituitary adenomas, submitted to endoscopic endonasal removal with a subsequent follow up from 3 to 36 months, from January 2005 to September 2008. They reported that $100 \%$ (7) of patients with microadenoma and $43 \%$ (13) of patients with macroadenoma had a total resection of tumors (17). Gomez-Amador, in a large series of 167 patients with non-functional adenoma that had undergone endoscopic surgery reported that 60.20\% (59) of patients received up to a $90 \%$ tumor resection (18). Our results were a sign of our learning process and the fact that many of the patients were in an advanced state with regard to the disease. $25 \%$ (7) of the patients with microadenoma were totally resected. In our series, macroadenomas with sellar/supraselar and cavernous sinus extensions were common $75 \%$ (21) cases and gross macroscopical resection was done on $76 \%$ (16) of patients. On the other hand, the endocrinological outcomes for micro adenomas patients were better because it was possible to completely remove all of the tumors $(100 \%)$. There was a characteristic improvement in visual symptoms, with the greatest degree of improvement occurring within the first few months. MRI and perimetry played an important part in the post-treatment monitoring of patients.

Based on visual field perimetry, our rate of visual improvement after surgery $(78.5 \%)$ was similar to that reported by other studies $(16,17,19)$.

Santos et al. had a $47 \%(10 / 21)$ improvement in terms of visual interference in their series. Thus, our patients' satisfaction with their visual deficit improvement gives hope to us.

Common complications with regard to the endoscopic or microscopic transsphenoidal approach includes CSF leaks and meningitis (17,18,20-22). 16\% (5) patients of Americo Rubens had post-operation CSF leaks without any meningitis. CSF leaks were seen in $10 \%$ (3) of our patients, but it did not develop into meningitis. The preoperative CSF leak is probable due to lack of routine reconstruction of the sella turcica. Lately, the role of nasal vascularized flaps has proven superior as a means of avoiding CSF leaks (23). Therefore, we accepted that using this technique for reconstruction of the sella turcica was desirable, and we used it in 6 patients of 11 with intraoperative CSF leakage. The rate of vascular injuries related to the transnasal approach has been described in some series to be approximately $2 \%$, including subarachnoid hemorrhage and intraventricular bleeding (24), but we didn't experience any catastrophic vascular injury in our series. We found, based on the literature and the outcomes of our descriptive prospective study, that the endoscopic endonasal approach for pituitary adenomas is valuable and has low morbidity (17). In our follow up of the patients over a 4 year period, we believe that endoscopic pituitary surgery has far superior outcomes if surgeons have developed a good procedure and are familiar with endoscopic system and technique. Endoscopic pituitary surgery can be used for several cases of pituitary tumors such as acromegaly or gigantism, Cushing's disease, prolactinomas, adenomas invading the cavernous sinus and extending to the suprasellar area, and hormonally inactive adenomas. Complications of endoscopic pituitary surgery can be reduced as a result of the increase in surgical performance. These implications will be further substantiated with more extensive information and over longer follow up periods. Only when it is perfect will trans nasal endoscopic pituitary surgery represent a major improvement in the surgical management of pituitary disease. 


\section{Conclusion}

Despite its fast 'learning curve', our series determines that the endoscopic method not only offers well anatomical visualization and therefore facilitates full oncological resection of tumors, but it also cuts the incidence of peri-operative complications. To consider developing a practical understanding and learning about endoscopic surgery and the introduction of teamwork schedules is realistic.

\section{Acknowledgment}

The authors thank the patients who took part in this study.

\section{Funding}

None

\section{Conflicts of Interest}

The authors declared that they have no conflicts of interest.

\section{References}

1. Landolt, AM. History of transsphenoidal pituitary surgery. In Landolt, AM, Vance ML, Reilly, PL (Eds). Pituitary adenomas. London: Churchill Livingstone 1996:307314.

2. Rosegay, H. Cushing's legacy to transsphenoidal surgery. J Neurosurg 1981; 54: 448-454. PMID: 7009800

3. Guiot A. Transsphenoidal approach in surgical treatment of pituitary adenomas: general principles and indications in nonfunctioning adenomas. In: Kohler, PO, Ross, GT (Eds). Diagnosis and treatment of pituitary tumors. Amsterdam: Excerpta Medica, International Congress Series No 303, 1973:159-178.

4. Hardy, J. Transsphenoidal microsurgery of the normal and pathological pituitary. Clin Neurosurg 1969; 16:185-217.

5. Stammberger, H. Endoscopic endonasal surgery: concepts in treatment of recurring rhinosinusitis. Part II. Surgical technique. Otolaryngo Head Neck Surg 1986; 94:147-156. PMID: 3083326

6. Jankowski, R, Auque, J, Simon, C, Marchal, JC, Hepner, H, Wayoff, M. Endoscopic pituitary tumor surgery. Laryngoscope 1992; 102:198-202.

7. Jho, HD .Endoscopic endonasal pituitary surgery: technical aspects. Contemporary Neurosurgery 1997; 19:1-7.

8. Carrau, RL, Jho, HD, Ko, Y. Transnasal - Transsphenoidal endoscopic surgery of the pituitary gland. Laryngoscope 1996; 106:914-918. PMID: 8667994

9. Prevedello, DM, Doglietto, F, Jane, JA Jr, Jagannathan, J, Han, J et al. History of endoscopic skull base surgery: its evolution and current reality. J Neurosurg 2007; 107: 206-213. PMID: 17639897

10. Cappabianca, P, Alfieri, A, de Divitiis, E. Endoscopic endonasal transsphenoidal approach to the sella: towards functional endoscopic pituitary surgery (FEPS). Minim Invasive Neurosurg 1998; 2: 66-73. PMID: 9651913

11. Alfieri, A, Jho, HD. Endoscopic endonasal approaches to the cavernous sinus: surgical approaches. Neurosurgery 2001; 49: 354-360. PMID: 11504111

12. Jho, HD, Carrau, RL, Ko, Y, Daly, M. Endoscopic pituitary surgery: an early experience. Surg Neural 1997; 47:213-223. PMID: 9068690

13. Jho, HD, Alfieri, A. Endoscopic endonasal pituitary surgery: evolution of surgical technique and equipment in 150 operations. Minim Invasive Neuro $\neg$ surg 2001; 44:1-12. PMID: 11409304

14. Santos, Rde P, Zymberg, ST, Abucham Filho, JZ, Gregorio, LC, Weckx, LL. Endoscopic transnasal approach to sellar tumors. Braz J Otorhinolaryngol 2007; 73:463-475. PMID: 7009800.

15. Jho, HD, Carrau, RL. Endoscopic endonasal transsphenoidal surgery: experience with 50 patients. J Neurosurg 1997; 87:44-51. PMID: 9202264

16. Mortini, P, Losa, M, Barzaghi, R, Boari, N, Giovanelli M. Results of transsphenoidal surgery in a large series of patients with pituitary adenoma. Neurosurgery 2005; 56:1222-1233. PMID: 15918938

17. Santos, A., Neto, R., Veiga, J., et al. Endoscopic endonasal transsphenoidal approach for pituitary adenomas. Arq Neuropsiquiatr 2010;68 (4): 608-612.PMID: 7009800

18. Gomez-Amador, J.L, Martínez-Anda,J.J., Morales-Martínez, A.H, et al .Management of Complications in Endoscopic Endonasal Surgery for Pituitary Adenomas. J Neurol Disord2015;3:1. http://dx.doi.org/10.4172/2329-6895.1000209 19. Frank, G, Pasquini, E, Farneti, G, etal. The endoscopic versus the traditional approach in pituitary surgery. Neuroendocrinology 2006; 83:240-248. PMID: 17047389

20. Dehdashti, AR, Ganna, A, Karabatsou, K, Gentili, F. Pure Endoscopic Endonasal approach for pituitary adenomas: early surgical results in 200 patients and comparison with previous microsurgical series. Neurosurgery 2008; 62:1006-
1017. PMID: 18580798

21. Cappabianca, P, Cavallo, LM, Colao, A, de Divitiis, E. Surgical complications associated with the endoscopic endonasal transsphenoidal approach for pituitary adenomas. J Neurosurg 2002;97:293-298. PMID: 12186456

22. Ciric, I, Ragin, A, Baumgaetnerr, C, Pierce, D. Complications of transsphenoidal surgery: results of a national survey, review of the literature, and personal experience. Neurosurgery 1997;40:225-237. PMID: 9007854

23. Hadad, G, Bassagasteguy, L, Carrau, RL, et al. a novel reconstructive technique after endoscopic expanded endonasal approaches: vascular pedicle nasoseptal flap. Laryngoscope 2006; 116:1882-1886. PMID: 1700370

24. Wang, SS, Li, JF, Chen, HJ, Wang, RM. Clinical application of anatomy landmarks for microscopic endonasal transsphenoidal surgery for pituitary adenomas. J Craniofac Surg 2013;24: 1785-1789. PMID: 24036780. http://dx.doi. org/10.1097/SCS.0b013e3182a210ab. 